\title{
Composition of the Adhesive Used for Fixing Glass Eyes of the Stone Standing Maitreya of Daejosa Temple, Buyeo (Treasure No. 217)
}

\author{
Jongseo Park ${ }^{*}$, Sunmyung Lee \\ Cultural Heritage Conservation Science Center, National Research Institute of Cultural Heritage, Daejeon 34122, Korea
}

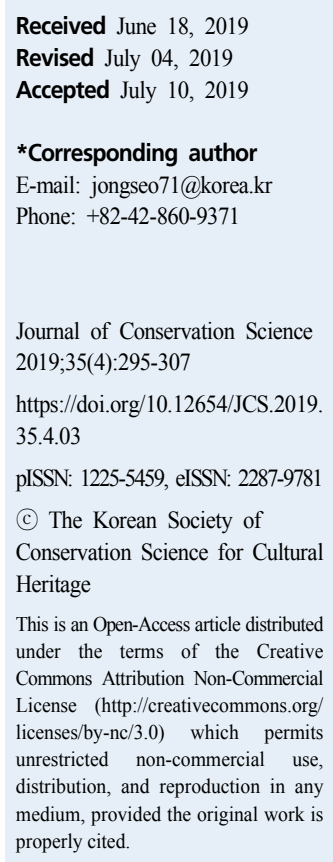

ABSTRACT In the process of the conservation treatment of the glass eyes of the stone standing Maitreya of Daejosa temple, Buyeo (Treasure No. 217), a blackish material, expected to be the adhesive for fixing the glass eyes, was collected and analyzed. Infrared spectroscopy and pyrolysis/gas chromatography/mass spectrometry (pyrolysis/GC/MS) were employed to identify the organic material in the sample. The IR analysis revealed the presence of materials such as apatite or bone black. The pyrogram of the sample was similar to that of Asian lacquer, among traditional adhesives. In particular, the pyrolysis/GC/MS analysis with online methylation detected 1,2-dimethoxy-3-pentadecylbenzene, methyl 7-(2,3- dimethoxyphenyl) heptanoate, and methyl 8-(2,3-dimethoxyphenyl)octanoate. These are known to be the pyrolysis products of catechol and its oxidation product, which indicated the presence of Asian lacquer in the sample. X-ray diffraction, X-ray fluorescence, and thermal gravimetry analysis showed that the sample contained ca. $60 \%$ inorganic substances, including apatite. Radiocarbon dating of the sample suggested that the blackish material was applied between the late $13^{\text {th }}$ and early $15^{\text {th }}$ century, revealing some discrepancy with the art-historical manufacturing time of the Maitreya. From the above analysis, it was concluded that Asian lacquer and bone ash were used to attach the glass eyes by forming a thick blackish lacquer layer.

Key Words The stone standing Maitreya of Daejosa temple, Glass eye of stone Buddha, Asian lacquer, Bone ash, Pyrolysis/GC/MS

\section{INTRODUCTION}

Requests were received for the conservation treatment of the eyes of the stone standing Maitreya (Treasure No. 217) of Daejosa temple, Buyeo, Chungcheongnam-do in the course of its emergency maintenance. In the process of removing the glass eyes for the conservation treatment, the components of materials assumed to be the adhesive covering around the glass eyes were analyzed and the period in which they were used was estimated.

\subsection{The eyes of stone standing Maitreya of Daejosa temple (Treasure No. 217)}

The stone standing Maitreya of Daejosa temple, Buyeo (Treasure No. 217) is located in Imcheon-myeon, Buyeo, Chungcheongnam-do, South Korea. It is composed of massive coarse-grained biotite granite with a height of approximately $8.64 \mathrm{~m}$ and a maximum width of $4.2 \mathrm{~m}$. It is unclear when the stone Maitreya was created; however, because its size and style are similar to those of stone standing Maitreya of Gwanchok temple, Nonsan, it is estimated that the date of creation was around 950-970 $\mathrm{AD}$ (Buyeogun, 1999; Jeong, 2007). The glass eyes were inserted by chiseling holes on the iris of the stone Maitreya which are slightly larger than an eye. 
(A)

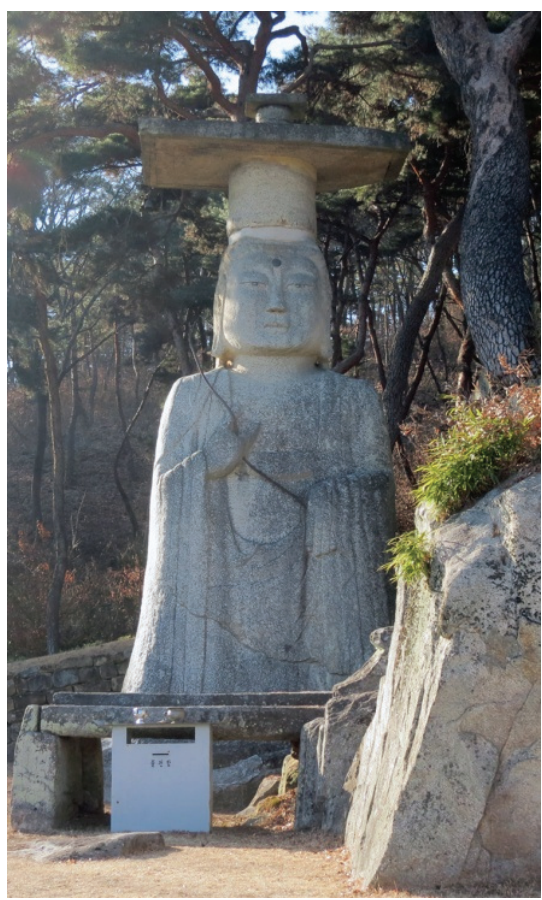

(B)

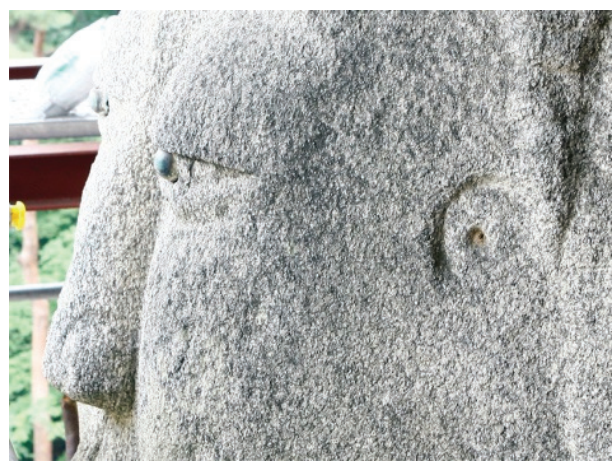

(C)

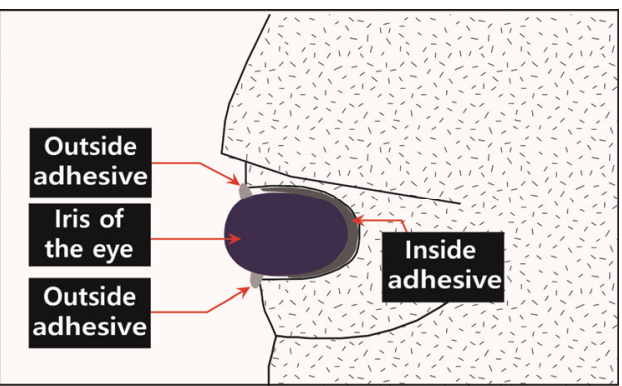

Figure 1. Photographs and diagram of the object. (A) Stone standing Maitreya of Daejosa temple, Buyeo, (B) Glass eye and (C) Schematic representation of the installed glass eye.

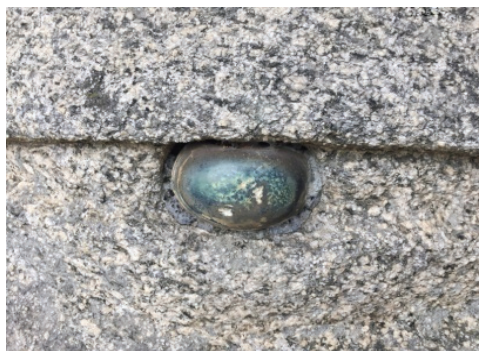

(A)

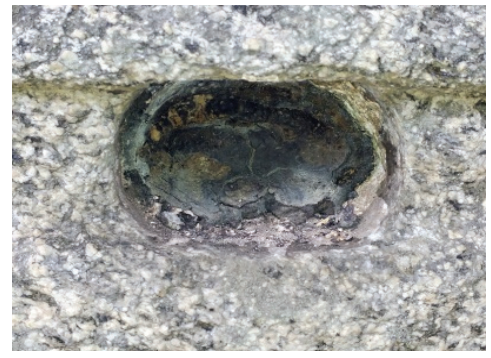

(B)
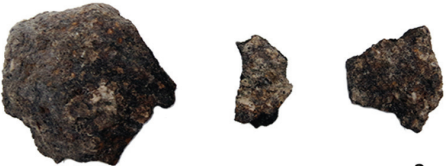

$2 \mathrm{~cm}$

(C)

Figure 2. Appearance of the fixing material before and after unjoining the glass eye. (A) Before unjoining the glass eye, (B) After unjoining the glass eye and (C) Fixing material collected from the back of right eye.

It was assumed that after applying the adhesive inside the eye holes, the glass eyes were pushed in; then, while a part of the glass eye was still exposed, the adhesive was filled in between the glass eye and the hole, thereby bonding them(Figure 1).

When separating the glass eyes from the eye holes, after removing the outside adhesive, the glass eyes were detached and the adhesive remaining inside the holes was removed. Accordingly, the adhesives were collected and classified as either outside adhesive or inside adhesive. The adhesives were generally black and hard but felt light despite its dense structure. The amount of outside adhesive collected was smaller than that of the inside adhesive. Furthermore, when the adhesives were collected on site, the outside adhesive appeared to be brighter in color and lighter in weight than the inside adhesive, thereby showing some differences in properties(Figure 2).

\subsection{Analysis of Asian lacquer-based traditional adhesive}

Traditional adhesives were used before synthetic resin adhesives were developed in the modern era, and they are largely classified into organic adhesives and inorganic adhesives. 
Among the organic adhesives, animal adhesives include shellac, egg white, milk, cheese, and animal glue; plant adhesives include Asian lacquer, natural rubber, pine resin, ulmi cortex, and adhesives extracted from rice and wheat(Yang, 2016). As long periods of time pass, the adhesives are discovered weathered under the ground, or remain in the shape of artifacts, such as craft items and household items. To investigate the types of traditional adhesives, many studies have been conducted to analyze their components. There have been abundant analysis results reported for Asian lacquer, which is known to have excellent durability, because many Asian lacquer samples exist till date. Lu et al. (2013) investigated the components of Asian lacquer and established a marker for identifying lacquer and reported a case study confirming the presence of Asian lacquer in excavated artifacts. Wei et al. (2011) also analyzed a lacquerware artifact discovered in a tomb from the Warring States period in ancient China by using pyrolysis/gas chromatography/mass spectrometry (pyrolysis/GC/MS), and detected 3-pentadecenylcatechol and 3-pentadecylcatechol in the sample and the reference. Then, based on their results that 3-heptylcatechol was detected maximally among the phenol types, they confirmed that the corresponding artifact was lacquerware. Schilling et al. (2016) systematically summarized the results of previous studies related to the analysis of organic materials in Asian lacquer, so that the existence/non-existence and relative composition ratios of various organic composites in Asian lacquer such as drying oils, anacards, anacard oxidation products, proteins, carbohydrates, and resins could be estimated from the pyrolysis/GC/MS analysis results.

In South Korea, there have not been many cases of examining Asian lacquer through instrumental analysis. A few reports include a case of detecting pyrolyzed matter such as phenol, 2-propenylbenzene, 1-tetradecene, and pentadecane by performing pyrolysis/GC/MS analysis on lacquerware samples excavated in Shinchang-dong, Gwangju and Imdang-dong, Gyeongsan(Kim, 2007); a case of detecting components originating from Asian lacquer, such as methylbenzene, 2-hydroxy-4-methylphenol, 3-tetradecene, and pentadecane, by performing pyrolysis/GC/MS analysis on the adhesives used in a great jar of the Proto-Three Kingdoms period(Cho et al., 2010); and a case of confirming an Asian lacquer sample from Nongso Tomb in Sunchang through infrared (IR) and pyrolysis/ GC/MS analyses(Naju National Research Institute of Cultural Heritage, 2016). Meanwhile, there have been cases of analysis showing that bone powder was used in the lacquer layer through the detection of calcium and phosphorous. Some examples related to this finding include a case of detecting calcium and phosphorous as main components in the lacquered layer of the dried-lacquer amitabha Buddha statue in Simhyang temple, thereby confirming that bone powder was used(Jeong and Myochin, 2014); a case of detecting calcium and phosphorous in the lacquered layer of a bowl and pot among the lacquerware items excavated at 849-16 Top-dong, Gyeongju, which were determined as artifacts of the Unified Silla period, thereby confirming that bone powder was used (Gyeong-Dam Conservation Laboratory, 2010). In addition, there are many reports confirming the presence of a bone powder layer in the lacquered layer of Najeon-lacquerware items (lacquerware items inlaid with mother-of-pearl) from the Goryeo and Joseon periods(Yi, 1996; Choi et al., 2011). Furthermore, it is mentioned in "On Lacquer Decoration" (Xiushilu, 髹飾錄) that for coating, horn-ash is of the best grade and bone-ash is of medium grade, and it is recorded in “Fundamentals of Lacquer Decoration”(Xiushilu jieshuo, 髹飾錄箋 證) that the ash of deer bone is of the best grade, followed by bullhorn(Jeong and Myochin, 2014). It is ascertained from these results that a technique of burning and grinding bones and mixing them to form the coating has been used since ancient times.

\subsection{Purpose of research}

Following the analysis of the material properties of the glass used in the eyes of the stone standing Maitreya of Daejosa temple(Lee et al., 2018), this study aims to investigate the materials and composition ratio used in the adhesive by analyzing the adhesives fixing the glass eyes. Furthermore, this study estimates the period in which the adhesive was applied to the glass eyes by radiocarbon dating of the adhesive. Thus, the original components of the adhesive are investigated in order to acquire necessary information for the reproduction of adhesive when reinstalling the eyes in the future.

\section{EXPERIMENTS}

\subsection{Materials and reagents}

The traditional adhesives used for comparison with the samples were animal glue, dendropanax lacquer, and Asian 
lacquer. For the animal glue, a small lump of glue(pearl glue, Nakagawa, JPN) was dissolved in water, of which $0.2 \mathrm{mg}$ was added into a pyrolysis cup. For the Asian lacquer, crude lacquer produced in Wonju was dried and ground, and approximately $0.5 \mathrm{mg}$ of the powder was added into a pyrolysis cup. The dendropanax lacquer produced in Wando was dried and ground, and about $0.5 \mathrm{mg}$ of the powder was used. When performing the pyrolysis, $10 \mu \mathrm{L}$ tetramethylammonium hydroxide solution (TMAH, 25 wt $\%$ in water)(Sigma-Aldrich, USA) was used for on-line methylation.

\subsection{Adhesive samples}

The adhesive samples used were collected when the glass eyes were separated. The outside adhesive exposed to the outside and the inside adhesive existing deep inside the eye holes were classified and analyzed. The collected samples were placed in a mortar and ground to a fine powder until homogeneity was achieved. Then, they were used for IR analysis, pyrolysis/GC/MS analysis, inorganic matter analysis, and radiocarbon dating.

\subsection{Analysis methods}

\subsubsection{Microstructural characteristic analysis}

A cross-section of an adhesive sample was fixed with epoxy resin. Then, the cross-section was polished with sandpaper starting from \#500 and ending at \#2400, and finished with $1 \mu \mathrm{m}$ and $3 \mu \mathrm{m}$ abrasives. After polishing, to examine the microstructural characteristics of the cross-section of the adhesive, the surface was examined using a stereoscopic microscope(Stemi 2000C and Axiotech, Carl Zeiss, DEU) and a polarization microscope(Axioplan2, Carl Zeiss, DEU). For microstructural observation and semi-quantitative component analysis, Pt/Pd was coated onto the samples; next, scanning electron microscopy (SEM)(JSM-IT300, Jeol, JPN) with an energy dispersive spectroscopy (EDS) analyzer $\left(\mathrm{X}-\mathrm{MAX}^{\mathrm{N}}\right.$, Oxford, GBR) was used. Here, accelerating voltage was $20 \mathrm{kV}$, probe number was 60 , and working distance was set to $10 \mathrm{~mm}$.

\subsubsection{IR analysis}

For the IR analysis of samples, the attenuated total reflection (ATR) method was used. By using Thermo Fisher Scientific's Nicolet iS5 model(USA) equipped with a diamond crystal, the measurements were performed by scanning 16 times with $4 \mathrm{~cm}^{-1}$ resolution in the range of 4,000-550 $\mathrm{cm}^{-1}$.

\subsubsection{Pyrolysis/GC/MS Analysis}

Frontier Lab's PY-3030D model(JPN) was used for the pyrolyzer, and Agilent's 7890A GC/5975C MSD model(USA) was used for the GC/MS analysis. A certain amount of sample was added into a pyrolysis cup without special pretreatment; next, it was inserted in a preheated pyrolyzer and pyrolyzed at $500^{\circ} \mathrm{C}$ for $0.2 \mathrm{~min}$. Here, when derivatization was required, the pyrolysis was performed after applying $10 \mu \mathrm{L}$ TMAH. The products of pyrolysis were analyzed on-line by using the GC/MS, and the analysis conditions were as follows. For the analysis column, a DB-1HT column(100\% dimethylpolysiloxane, $30 \mathrm{~m} \times 0.25 \mathrm{~mm}$ id, $0.10 \mu \mathrm{m}$ film thickness) was used, and after holding the temperature at $50^{\circ} \mathrm{C}$ for $3 \mathrm{~min}$, it was heated to $300^{\circ} \mathrm{C}$ at a rate of $10^{\circ} \mathrm{C} / \mathrm{min}$ and maintained at temperature for $5 \mathrm{~min}$, thereby analyzing for a total of $33 \mathrm{~min}$. Helium( 0.5 $\mathrm{mL} / \mathrm{min}$ ) was used for the mobile phase gas, and a mass spectrometric detector (MSD) was used for detection. The data acquisition and analysis were performed by using Chemstation software(Agilent Technologies, USA) and NIST MS search program(The National Institute of Standards and Technology, USA).

\subsubsection{Inorganic matter analysis}

To analyze the inorganic matter contained in the samples, $\mathrm{X}$-ray diffraction (XRD) analysis, X-ray fluorescence (XRF) analysis, and thermogravimetric analysis (TGA) were performed. To identify the minerals composing the adhesives, an XRD analyzer(Empeyrean, PANalytical, NLD) was used. Here, a $\mathrm{Cu}$ $\mathrm{Ka} \mathrm{X}$-ray source was used with a voltage and current of 40 $\mathrm{kV}$ and $40 \mathrm{~mA}$, respectively, the scanning interval was set to $0.02^{\circ}$, and scans were conducted over a range of $10-80^{\circ}$; the diffraction values were recorded using the continuous scanning method. To investigate the composition of the main components of the adhesives, a wavelength-dispersive X-ray fluorescence spectrometer(PW2540, Philips, NLD) was used. The composition ratio of inorganic and organic matter was estimated based on the results of XRF analysis and TGA. In the TGA analysis, a Setsys Evolution(Setaram Inc., FRA) device was used, and according to the measurement conditions, the samples were heated from $0^{\circ} \mathrm{C}$ to $1,000^{\circ} \mathrm{C}$ at $20^{\circ} \mathrm{C} / \mathrm{min}$ in a $\mathrm{N}_{2}$ gas atmosphere. 


\subsubsection{Radiocarbon dating}

The radiocarbon dating of adhesive samples was done by Beta Analytic Inc.(Florida, USA). The pretreatment of the samples was performed with an acid/alkali/acid method. "Conventional radiocarbon age" was calculated by using the Libby half-life(5568 years) and then compensated for $\delta^{13} \mathrm{C}$. The age was rounded off to the nearest decade and shown as radiocarbon years before present(BP age; present $=\mathrm{AD}$ 1950). For the conversion of BP age into calendar year, the INTCAL13 database and high-probability density range (HPD) method were used, and the calendar years showing $95.4 \%$ and $68.2 \%$ probability, respectively, were obtained(Ramsey, 2009; Reimer et al., 2013).

\section{RESULTS AND DISCUSSION}

\subsection{Analysis of microstructural characteristics}

Optical microscope images of the surface of polished adhesives are shown in Figure 3. In the inside and outside adhesives, irregular micro-particles were observed with various colors such as white, gray, and black. The particle size was diverse, up to roughly $400 \mu \mathrm{m}$, and black or brown substances were filled in between these particles. In other words, particles of various sizes were embedded within the black and brown matrix. Meanwhile, the matrix showed brown lumps or black belt shapes.

When observed using the polarization microscope after the preparation of a thin slice, the micro-particles did not show the characteristics of minerals, and large porosity was observed (Figure 4). In some, canaliculi or cylindrical structures of the haversian system, a basic unit of bone tissue that comprises the cortical bones of mammals, reptiles, and amphibians, were observed in considerably small amounts(Kang et al., 2014). In addition, the SEM observations confirmed the histological characteristics of the haversian system, a basic unit of bone tissue such as lamellae, lacuna, canaliculi, and harversian canals where blood vessels and nerves pass through. Furthermore, $\mathrm{Ca}$ and $\mathrm{P}$ were detected as the main components in all the bone micro-particles, which were confirmed as bone tissues. Therefore, it was determined that they were hydroxyapatite, an inorganic material of bone tissue. On the other hand, $\mathrm{C}$ was detected in the surrounding matrix, suggesting that the matrix was composed of organic materials(Table 1, Figure 5).
(A)

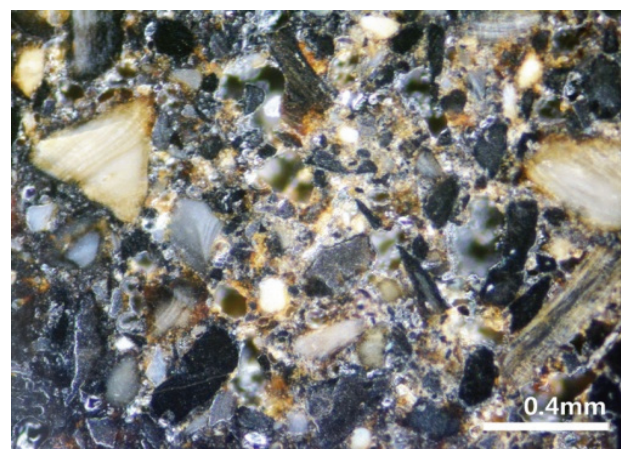

(C)

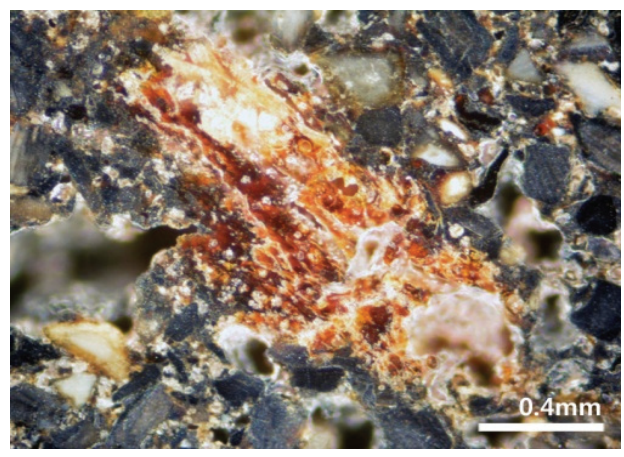

(B)

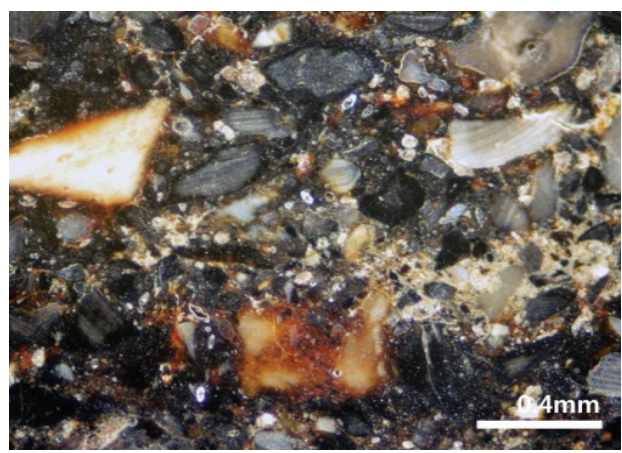

(D)

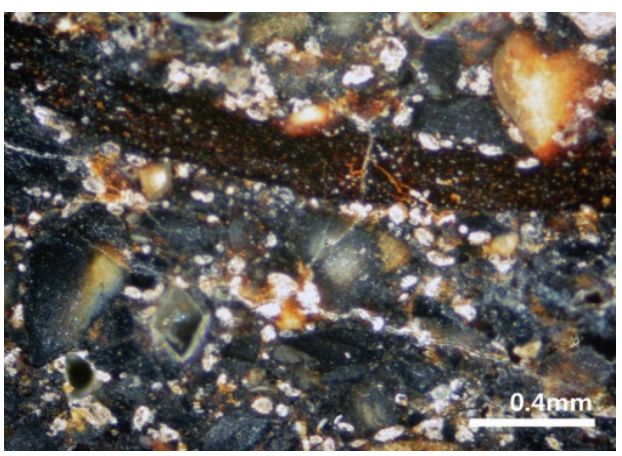

Figure 3. Optical microscopic images of the cross section of the fixing material. (A) Sample from the side of the glass eye and (B)-(D) Sample from the back of the glass eye. 

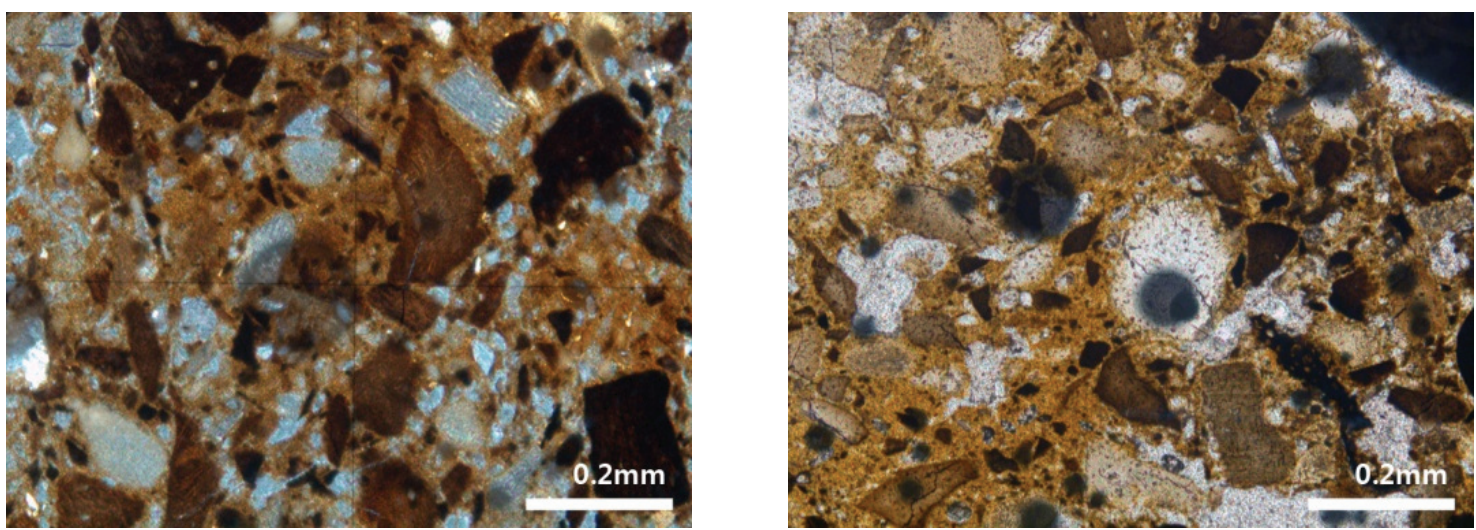

Figure 4. Polarized optical microscopic images of the sample from the back of the glass eye.

Table 1. Elemental mapping results of the cross-section of the sample from the back of the glass eye by EDS

\begin{tabular}{c|c|c|c|c|c|c|c|c|c|c|c|c|c}
\hline Element & $\mathbf{C}$ & $\mathbf{O}$ & $\mathbf{~ N a}$ & $\mathbf{A l}$ & $\mathbf{S i}$ & $\mathbf{P}$ & $\mathbf{C l}$ & $\mathbf{K}$ & $\mathbf{C a}$ & $\mathbf{F e}$ & $\mathbf{C o}$ & $\mathbf{A s}$ & total \\
\hline $\begin{array}{c}\text { Composition } \\
(\mathrm{wt} \%)\end{array}$ & 47.05 & 29.57 & 0.20 & 0.04 & 0.05 & 7.20 & 0.27 & 0.04 & 15.48 & 0.03 & 0.01 & 0.06 & 100.00 \\
\hline
\end{tabular}
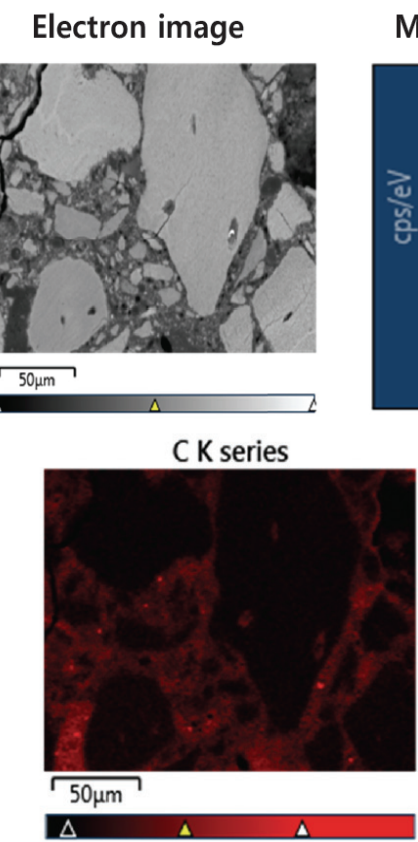

\section{Map sum spectrum}
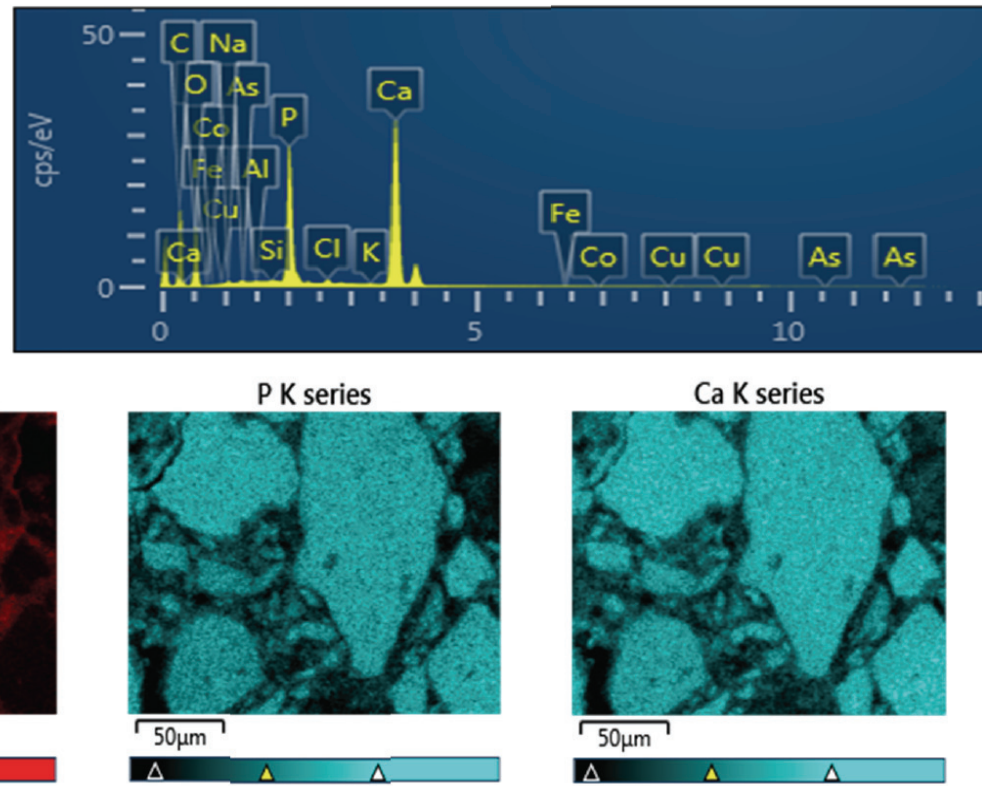

Figure 5. SEM image and EDS spectrum of the cross-section of the sample from the back of the glass eye.

\subsection{IR analysis}

Figure 6 shows the IR spectra of adhesive samples collected from the glass eyes. Considering that the samples from the side and the back of the right glass eye, and the back of the left glass eye all showed the same spectral features, it was determined that the samples were composed of the same materials. First, in the case of an organic material showing a large peak at $3369 \mathrm{~cm}^{-1}$ corresponding to $\mathrm{OH}$ stretching, the oxidation seemed to have progressed a lot. The peaks appearing at 2930 and $2858 \mathrm{~cm}^{-1}$ correspond to C-H stretching, indicating this sample contained an organic material. The absorption at 


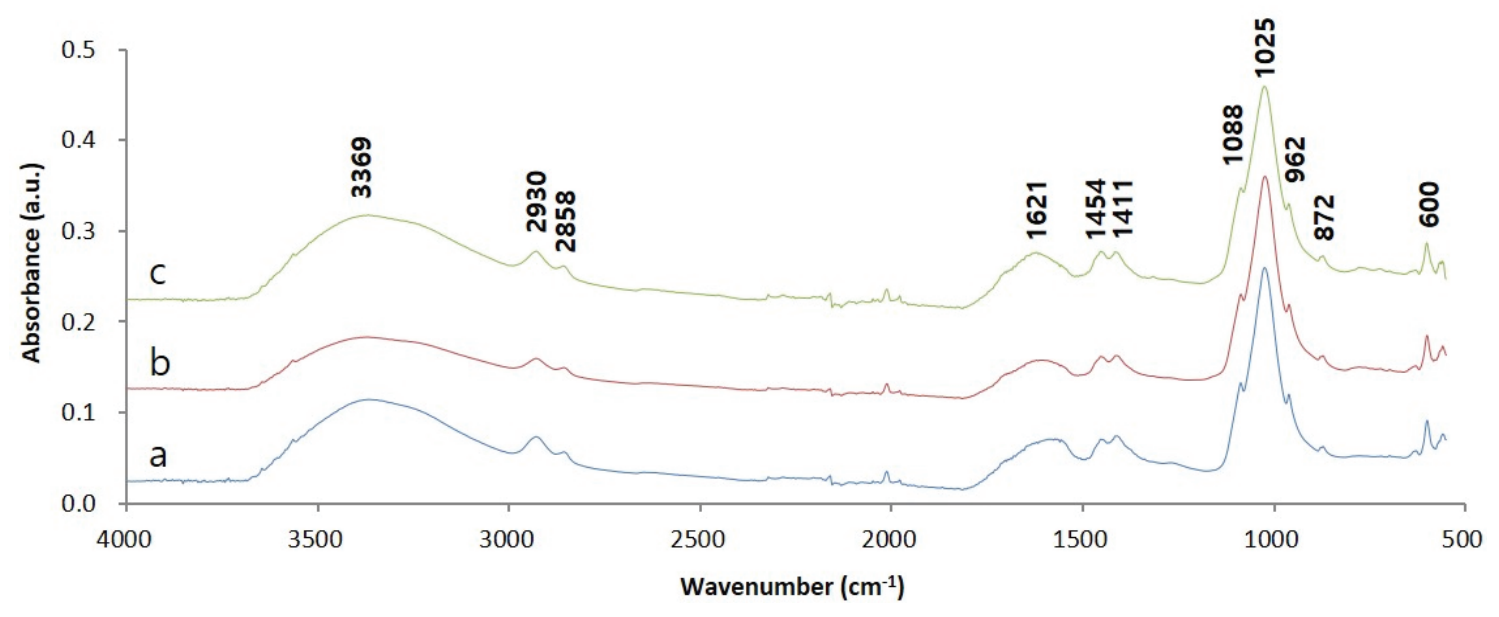

Figure 6. IR spectra of the samples. (a) Sample from the back of the left glass eye, (b) Sample from the back of the right glass eye and (c) Sample from the side of the right glass eye.

around $1025 \mathrm{~cm}^{-1}$ and the absorption at around $1410 \mathrm{~cm}^{-1}$ correspond to C-O stretching(alcohols, ethers, esters, etc.), C-N stretching(amine), C-H bending(- $\left.\mathrm{CH}_{3}\right)$, and $\mathrm{C}-\mathrm{F}$ stretching in the case of organic materials. However, in the results previously published in the literature, spectral features at wavelengths less than or equal to $1600 \mathrm{~cm}^{-1}$ were consistent with the characteristic spectrum of a material containing phosphates such as bone black, ivory black, and apatite(Lee et al., 2014; Institute of Chemistry University of Tartu, Estonia, 2019). In other words, the peaks at 600,962 , and $1025 \mathrm{~cm}^{-1}$ result from $\mathrm{PO}_{4}{ }^{3-}$ and those at 872,1411 , and $1454 \mathrm{~cm}^{-1}$ result from $\mathrm{CO}_{3}^{2-}$. Therefore, from the IR analysis results, it was ascertained that the adhesives contained inorganic materials containing phosphates along with organic materials. Meanwhile, the IR spectra of dendropanax lacquer, Asian lacquer, and animal glue obtained previously(Park and Lee, 2017) were compared to estimate the type of organic materials; however, it was difficult to find a similarity.

\subsection{Pyrolysis/GC/MS analysis}

\subsubsection{Comparison with traditional adhesives}

Figure 7 shows the pyrolysis/GC/MS chromatograms of adhesive samples obtained from the glass eyes as well as

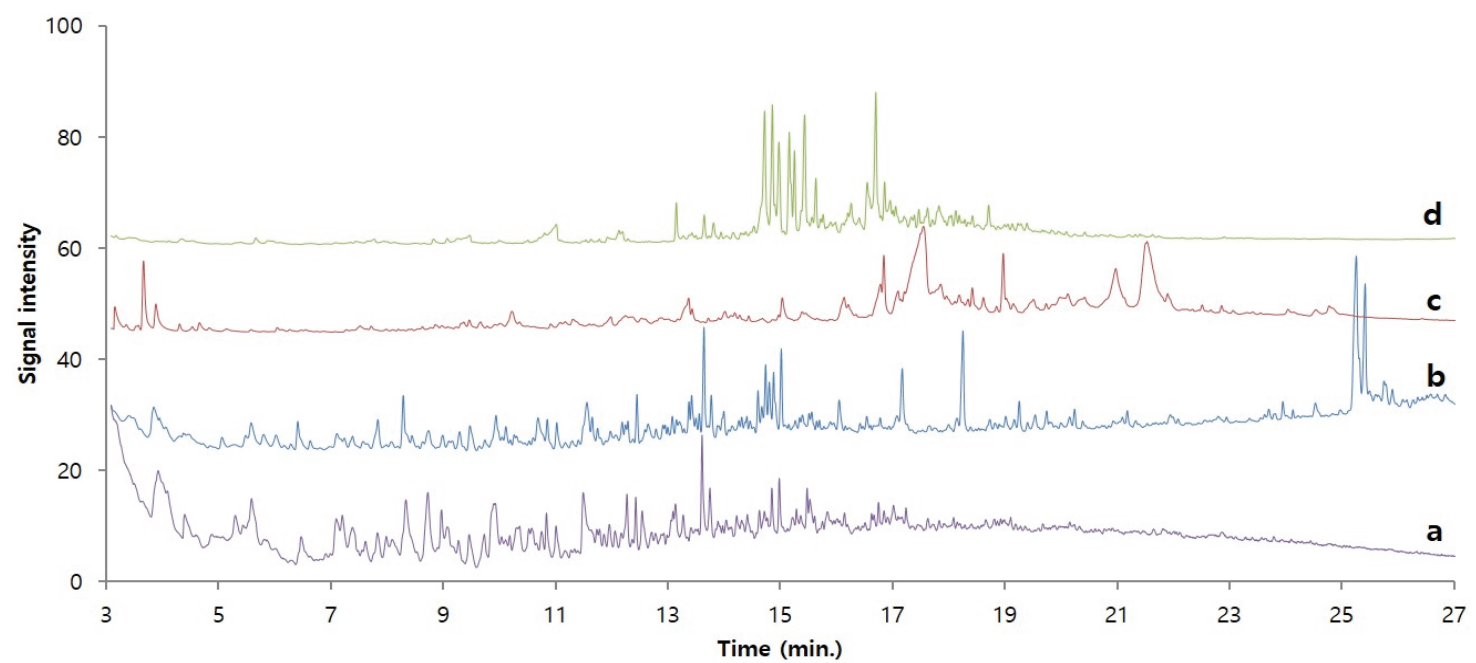

Figure 7. Pyrolysis/GC/MS chromatograms of adhesive sample and traditional adhesives. (a) Sample $(\times 10)$, (b) Dried Asian lacquer, (c) Animal glue (×4) and (d) Dried yellow lacquer(from Dendropanax morbiferus). 
traditional adhesives(Asian lacquer, animal glue, and dendropanax lacquer). For convenience of comparison, the chromatograms of adhesive samples and animal glue were magnified by ten times and four times, respectively, so that they are of a similar size as the other reference chromatograms. Considering the characteristics of pyrolysis/GC/MS analysis, which shows almost identical chromatograms when the polymer components are the same, it seems there is no substance that shows an identical chromatogram among the samples and three traditional adhesives. However, until approximately $18 \mathrm{~min}$ of retention time, the chromatogram of dried Asian lacquer showed a similar pattern as the chromatogram of the adhesive sample. Therefore, there is a strong possibility that the sample contained dried Asian lacquer.

\subsubsection{Confirmation of Asian lacquer by on-line derivatization analysis}

A polymeric substance, which has been weathered for a long time, contains a lot of organic acids and alcohols as its degradation products. However, organic acids and alcohols are difficult to detect selectively in a hydrophobic column such as a polydimethylsiloxane column because of their strong polarity. To solve this problem, before injecting the sample into the GC, its polarity is decreased by undergoing a derivatization reaction such as methylation and silylation. Here, TMAH and the sample were pyrolyzed together to produce a methylation reaction with the organic acids and alcohols so that the analysis efficiency and sensitivity will be increased. Figure 8 shows the pyrolysis/GC/MS chromatograms of dried Asian lacquer and the adhesive sample obtained through the on-line derivatization process. Here, for the convenience of comparison, the chromatogram of the adhesive sample is shown three times larger than its actual size. First, to investigate the components of the detected peaks, a NIST library search was performed for each peak, and the major components are shown in Table 2 based on the retention time. First, the following compounds were commonly observed: propanoic acid, 2-methoxy-, methyl ester(1), 2,3dimethoxytoluene(15), tridecane(19), 1,2,4-trimethoxybenzene (21), 1-tetradecene(23), 1-tridecene(27), 1,2-dimethoxy-3hexylbenzene(32), 1,2-dimethoxy-3-heptylbenzene(35), hexadecanoic acid, methyl ester(37), methyl 7-(2,3-dimethoxyphenyl) heptanoate(38), methyl 8-(2,3-dimethoxyphenyl)octanoate(40), and 1,2-dimethoxy-3-pentadecylbenzene(44). Particularly, 2,3dimethoxytoluene, 1,2-dimethoxy-3-hexylbenzene, 1,2dimethoxy-3-heptylbenzene, and 1,2-dimethoxy-3-pentadecylbenzene are derivative components of catechol appearing when urushiol, a main component of Asian lacquer, is pyrolyzed in the presence of TMAH and methylation occurs; they indicate

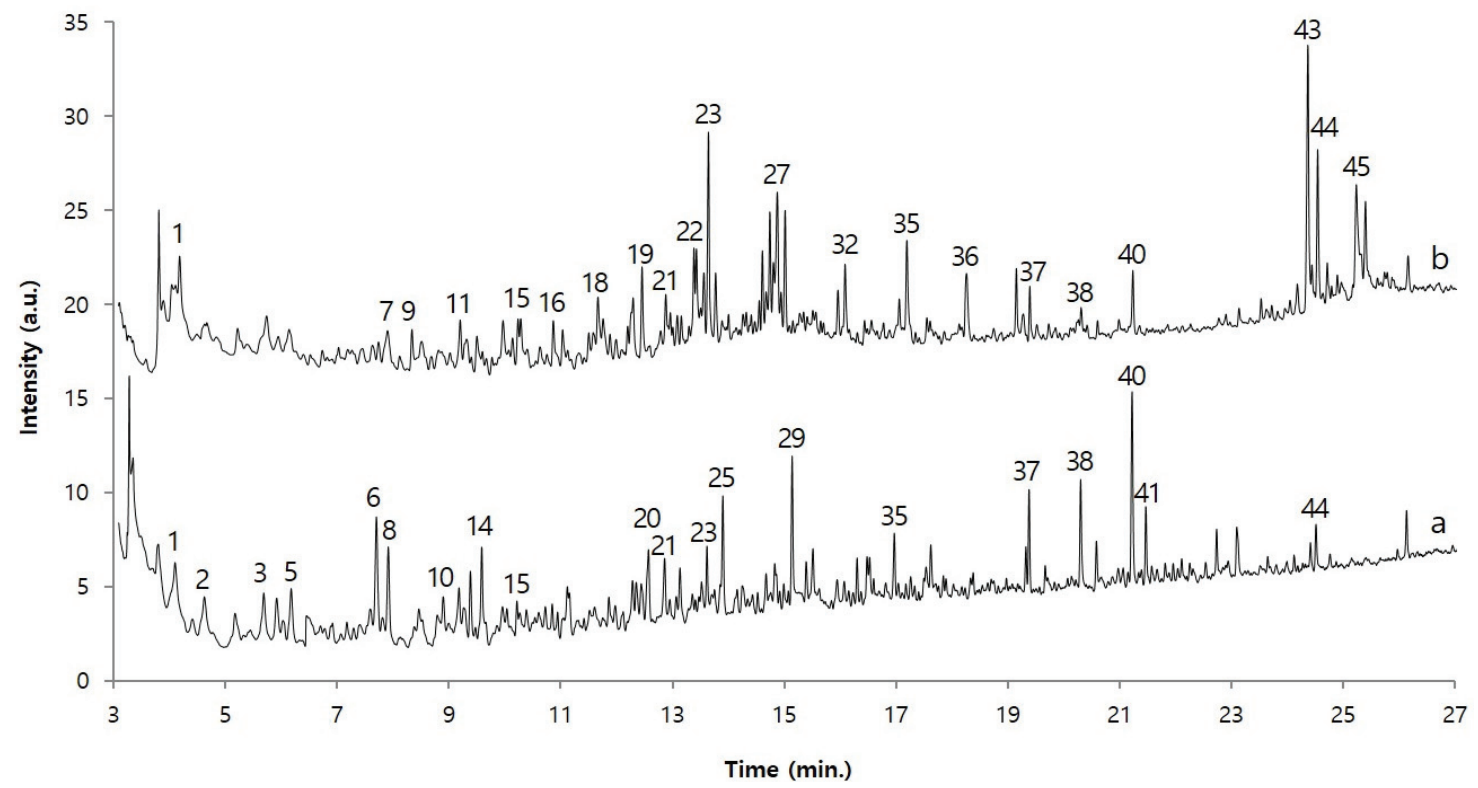

Figure 8. Pyrolysis/GC/MS chromatograms of sample and dried Asian lacquer(on-line methylation with TMAH). (a) Sample $(\times 3)$ and (b) Dried Asian lacquer. 
Composition of the adhesive used for fixing glass eyes of the Stone Standing Maitreya of Daejosa Temple, Buyeo (Treasure No. 217) / Jongseo Park, Sunmyung Lee I 303 Composilion of the adhesive ued for fixng glas eyes of he Stone Stand

Table 2. Components of dried Asian lacquer and adhesive sample from the eyes of the stone standing Maitreya of Daejosa temple, Buyeo (Treasure No. 217) analyzed by pyrolysis/GC/MS with on-line methylation

\begin{tabular}{|c|c|c|c|c|c|c|c|c|}
\hline No. & Name & $\underset{\text { (min.) }}{\text { RT_r }}$ & $\begin{array}{c}\text { RT_s } \\
\text { (min.) }\end{array}$ & Q_r & Q_s & 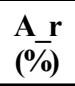 & $\begin{array}{l}\text { A_s } \\
(\%)\end{array}$ & Major ion $(\mathbf{m} / \mathbf{z})$ \\
\hline 1 & Propanoic acid, 2-methoxy-, methyl ester & 4.19 & 4.10 & 94 & 90 & 0.09 & 0.06 & $59,88,43$ \\
\hline 2 & Pentanoic acid, methyl ester & & 4.63 & & 86 & & 0.02 & $74,60,85,87,43$ \\
\hline 3 & Pentanoic acid, 3-methyl-2-oxo-, methyl ester & & 5.69 & & 83 & & 0.04 & $57,41,85$ \\
\hline 4 & 5-Hexenoic acid, methyl ester & & 5.92 & & 88 & & 0.08 & $74,68,43,97,55$ \\
\hline 5 & Hexanoic acid, methyl ester & & 6.18 & & 95 & & 0.10 & $74,43,87,59,99$ \\
\hline 6 & 6-Heptenoic acid, methyl ester & & 7.71 & & 95 & & 0.11 & $74,110,59,55,68,82$ \\
\hline 7 & Benzene, 1-propenyl- & 7.91 & & 90 & & 0.06 & & $117,91,63$ \\
\hline 8 & Heptanoic acid, methyl ester & & 7.92 & & 91 & & 0.11 & $74,87,43,113$ \\
\hline 9 & Acetophenone & 8.34 & & 97 & & 0.08 & & $105,77,120,51$ \\
\hline 10 & Benzoic acid, methyl ester & & 8.90 & & 97 & & 0.05 & $105,77,136,51$ \\
\hline 11 & Phenol, 2,5-dimethyl- & 9.19 & & 90 & & 0.02 & & $122,107,77$ \\
\hline 12 & 4-Octenoic acid, methyl ester & & 9.39 & & 99 & & 0.09 & $74,55,96,82,41,124$ \\
\hline 13 & Undecane & 9.50 & & 86 & & 0.05 & & $57,43,71,85,156$ \\
\hline 14 & Octanoic acid, methyl ester & & 9.59 & & 94 & & 0.10 & $74,87,43,127$ \\
\hline 15 & 2,3-Dimethoxytoluene & 10.24 & 10.22 & 94 & 93 & 0.05 & 0.02 & $152,137,109,91,77,65$ \\
\hline 16 & 1-Dodecene & 10.87 & & 90 & & 0.05 & & $55,69,83,41,97$ \\
\hline 17 & Dodecane & 11.04 & & 86 & & 0.05 & & $57,43,71,85,170$ \\
\hline 18 & Benzene, hexyl- & 11.67 & & 81 & & 0.04 & & $91,92,162,105$ \\
\hline 19 & Tridecane & 12.45 & 12.44 & 91 & 91 & 0.12 & 0.03 & $57,71,43,85,139$ \\
\hline 20 & Benzoic acid, 4-methoxy-, methyl ester & & 12.47 & & 90 & & 0.02 & $135,166,107,77$ \\
\hline 21 & 1,2,4-Trimethoxybenzene & 12.88 & 12.86 & 94 & 95 & 0.08 & 0.06 & $153,168,125,110$ \\
\hline 22 & Cyclododecene, (E)- & 13.39 & & 85 & & 0.12 & & $67,81,55,41,96,166$ \\
\hline 23 & 1-Tetradecene & 13.65 & 13.62 & 97 & 94 & 0.29 & 0.06 & $55,83,97,43,69,111$ \\
\hline 24 & Tetradecane & 13.78 & & 94 & & 0.06 & & $57,71,43,85,198$ \\
\hline 25 & Octanedioic acid, dimethyl ester & & 13.9 & & 96 & & 0.12 & $129,69,97,55,171$ \\
\hline 26 & Cyclopentadecane & 14.74 & & 85 & & 0.11 & & $69,55,83,97,41,210$ \\
\hline 27 & 1-Tridecene & 14.88 & 14.86 & 90 & 82 & 0.12 & 0.02 & $55,83,69,97,43$ \\
\hline 28 & Pentadecane & 15.02 & & 94 & & 0.15 & & $57,71,43,85,212$ \\
\hline 29 & Nonanedioic acid, dimethyl ester & & 15.14 & & 98 & & 0.14 & $152,55,74,111,185$ \\
\hline 30 & 3,4-dimethoxy benzoic acid, methyl ester & & 15.51 & & 93 & & 0.05 & $196,165,79,115$ \\
\hline 31 & 1,2-Dimethoxy-3-hexenylbenzene & & 15.95 & & 83 & & 0.01 & $136,220,151,91,177$ \\
\hline 32 & 1,2-Dimethoxy-3-hexylbenzene & 16.09 & 16.07 & 91 & 90 & 0.06 & 0.01 & $136,222,152,91$ \\
\hline 33 & Decanedioic acid, dimethyl ester & & 16.3 & & 95 & & 0.04 & $55,74,125,98,199$ \\
\hline 34 & Benzoic acid, 3,4,5-trimethoxy-, methyl ester & & 16.97 & & 96 & & 0.08 & $226,211,195,155$ \\
\hline 35 & 1,2-Dimethoxy-3-heptylbenzene & 17.19 & 17.17 & 82 & 85 & 0.09 & 0.01 & $136,236,151,91$ \\
\hline 36 & 1,2-Dimethoxy-3-octylbenzene & 18.24 & & 88 & & 0.02 & & $250,136,151,91$ \\
\hline 37 & Hexadecanoic acid, methyl ester & 19.39 & 19.38 & 96 & 97 & 0.06 & 0.10 & $74,87,143,227,270$ \\
\hline
\end{tabular}




\begin{tabular}{l|l|c|c|c|c|c|l|l}
\hline 38 & Methyl 7-(2,3-dimethoxyphenyl)heptanoate & 20.31 & 20.3 & 88 & 93 & 0.02 & 0.11 & $136,280,151,91$ \\
\hline 39 & 8-Methoxytetradecanoic acid, methyl ester & & 20.58 & & 83 & & 0.04 & $187,97,55,129,155$ \\
\hline 40 & Methyl 8-(2,3-dimethoxyphenyl)octanoate & 21.23 & 21.22 & 96 & 96 & 0.07 & 0.18 & $294,136,151,91$ \\
\hline 41 & 9,10-dimethoxyhexadecanoic acid, methyl ester & & 21.47 & & 96 & & 0.07 & $201,97,129,55,169$ \\
\hline 42 & Methyl 9-(2,3-dimethoxyphenyl)nonanoate & & 22.11 & & 92 & & 0.02 & $308,136,151,91$ \\
\hline 43 & 1,2-Dimethoxy-3-pentadec-8-enylbenzene & 24.37 & & 97 & & 0.43 & & $346,136,151,91,121$ \\
\hline 44 & 1,2-Dimethoxy-3-pentadecylbenzene & 24.54 & 24.51 & 97 & 96 & 0.17 & 0.04 & $348,151,136,91$ \\
\hline 45 & 3-Pentadecenylcatechol & 25.23 & & 82 & & 0.21 & & $123,136,318,149,55$ \\
\hline 46 & 3-Pentadecylcatechol & 25.39 & & 96 & & 0.10 & & $123,320,136$ \\
\hline
\end{tabular}

1) RT_r and RT_s signify the retention time in chromatograms of dried Asian lacquer(r) and that of the sample(s), respectively.

2) A_r and A_s signify the ratio of each peak area to total area in chromatograms of dried Asian lacquer(r) and that of the sample(s), respectively.

${ }^{3)}$ Q $r$ and Q_s signify matching quality of mass spectrum for dried Asian lacquer(r) and that for the sample(s), respectively.

that the adhesive sample obtained from the glass eyes contains Asian lacquer.

On the other hand, alkanes, alkenes, and catechols were mainly detected in the dried Asian lacquer, and the following acid materials produced by oxidation were detected in large amounts in the adhesive sample obtained from the glass eyes: pentanoic acid methyl ester(2), hexanoic acid methyl ester(5), 6-heptenoic acid, methyl ester(6), heptanoic acid, methyl ester(8), octanoic acid, methyl ester(14), benzoic acid, 4-methoxy-, methyl ester(20), octanedioic acid, dimethyl ester(25), nonanedioic acid, dimethyl ester(29), benzoic acid, 3,4,5-trimethoxy-, methyl ester(34), hexadecanoic acid, methyl ester(37), methyl 7-(2,3-dimethoxyphenyl)heptanoate(38), methyl 8-(2,3-dimethoxyphenyl)octanoate(40), 9,10- dimethoxyhexadecanoic acid, and methyl ester(41). Methyl 7-(2,3-dimethoxyphenyl)heptanoate, methyl 8-(2,3-dimethoxyphenyl) octanoate, and methyl 9-(2,3-dimethoxyphenyl)nonanoate detected in the adhesive sample from the glass eyes are known to be oxidation products of catechol(Schilling et al., 2016). Therefore, it was ascertained that the sample contains oxidized Asian lacquer components. Furthermore, the chromatograms of dried Asian lacquer and the adhesive sample from the glass eyes are not identical, and this seems to be simply because dried Asian lacquer and Asian lacquer that has been placed in a natural state for over hundreds of years have large differences due to weathering.

\subsection{XRD analysis of adhesive}

Apatite $\left[\mathrm{Ca}_{10}\left(\mathrm{PO}_{4}\right)_{6}(\mathrm{OH})_{2}\right]$, quartz, and feldspar were identified in the outside adhesive of the glass eyes, and apatite,

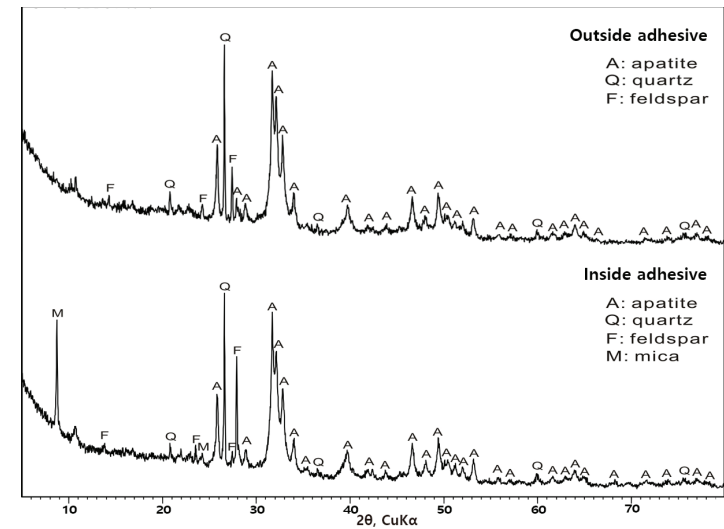

Figure 9. XRD results of the outside adhesive and the inside adhesive, respectively.

quartz, feldspar, and mica were identified in the inside adhesive (Figure 9). Based on this, it was determined that the outside adhesive of the glass eyes is mainly composed of apatite and tiny amounts of soil components such as quartz, feldspar, and mica.

\subsection{Elemental analysis of adhesive}

Elemental analysis of the main components of the adhesive from the glass eyes was performed targeting the inside adhesive only because it was confirmed that the inside and the outside adhesives of the glass eyes contained similar materials through the microstructural characteristics, FT-IR, pyrolysis/GC/MS, and XRD analysis presented above. The results are shown in Table 3. $\mathrm{P}_{2} \mathrm{O}_{5}$ and $\mathrm{CaO}$ were major components, showing 
$21.27 \mathrm{wt} \%$ and $29.42 \mathrm{wt} \%$ content, respectively. In addition,

$\mathrm{SiO}_{2}$ and $\mathrm{Al}_{2} \mathrm{O}_{3}$ showed $6.22 \mathrm{wt} \%$ and $1.17 \mathrm{wt} \%$ content, respectively. The remaining components were detected at less than $1 \mathrm{wt} \%$. This is consistent with the results of the above analysis confirming that the inorganic materials of the adhesive contained apatite having $\mathrm{Ca}$ and $\mathrm{P}$ as main components, and small traces of soil components. In the meantime, the chemical composition of granite is generally known to be $70-77 \%$ silica, $11-13 \%$ alumina, $3-5 \%$ potassium oxide, 3-5\% soda, and 2-3\% total iron(College of Natural Resources, UC Berkeley, 2019). In the elemental analysis of the adhesive, since the relative proportions of $\mathrm{SiO}_{2}, \mathrm{Al}_{2} \mathrm{O}_{3}, \mathrm{~K}_{2} \mathrm{O}, \mathrm{Na}_{2} \mathrm{O}$, and $\mathrm{Fe}_{2} \mathrm{O}_{3}$ are similar to those mentioned above, it is assumed that these components came from the granite, the material of the stone Maitreya. Loss on ignition (LOI) is a value calculated from the difference in mass before and after combustion when a sample is burned in a furnace and can be used to estimate the content of organic materials, which are combustible materials. Since the LOI is $39.59 \%$, it seems that the adhesive is composed of roughly $60 \%$ inorganic materials and $40 \%$ organic materials.

\subsection{Radiocarbon dating of adhesive}

Table 4 shows the results of radiocarbon dating of the adhesive of the glass eyes(Asian lacquer and bone powder). When the ${ }^{14} \mathrm{C}$ corrected age ( $95.4 \%$ confidence interval) was examined for each sample, the following results were found. For outside adhesive A, age divided into 1386-1434 AD and 1311-1359 AD were calculated. For B, 1388-1437 AD and 1316-1354 AD were calculated. For inside adhesive C, 1295$1404 \mathrm{AD}$ was calculated, and for D, 1343-1394 AD and 1280$1326 \mathrm{AD}$ were calculated. Based on these intervals, it was estimated that the adhesive was applied to the eyes of the stone Maitreya at some time between the late $13^{\text {th }}$ century and early $15^{\text {th }}$ century.

\section{CONCLUSION}

After analyzing the adhesive used for the glass eyes of the stone standing Maitreya of Daejosa temple, Buyeo, the following conclusions were reached.

1. In the shape of the adhesive, particles of various sizes were embedded in a black and brown matrix. Carbon was

Table 3. Elemental analysis results of sample from back of the glass eye by XRF and TGA

\begin{tabular}{|c|c|c|c|c|c|c|c|c|c|c|c|c|c|c|c|c|}
\hline Oxide & $\mathrm{Na}_{2} \mathrm{O}$ & MgO & $\mathbf{A l}_{2} \mathbf{O}_{3}$ & $\mathrm{SiO}_{2}$ & $\mathbf{P}_{2} \mathbf{O}_{5}$ & $\mathrm{SO}_{3}$ & $\mathrm{~K}_{2} \mathrm{O}$ & $\mathrm{CaO}$ & MnO & $\mathrm{Fe}_{2} \mathrm{O}_{3}$ & $\mathrm{CuO}$ & $\mathrm{ZnO}$ & $\mathrm{SrO}$ & PbO & LOI $^{1)}$ & Total \\
\hline $\begin{array}{c}\text { Portion } \\
(w t \%)\end{array}$ & 0.68 & 0.43 & 1.17 & 6.22 & 21.27 & 0.21 & 0.44 & 29.42 & 0.09 & 0.28 & 0.03 & 0.01 & 0.04 & 0.04 & 39.59 & 99.92 \\
\hline
\end{tabular}

1) LOI was estimated from the TGA result.

Table 4. Radiocarbon dating results for the samples from the side and back of the glass eye

\begin{tabular}{|c|c|c|c|c|c|c|}
\hline \multirow{2}{*}{ Sample } & \multicolumn{2}{|c|}{ Age (BP) } & \multicolumn{4}{|c|}{ Calendar calibrated results (AD) } \\
\hline & $\mathrm{CRA}^{1)}$ & $\mathrm{MRA}^{2)}$ & \multicolumn{2}{|c|}{$68.2 \%$ probability } & \multicolumn{2}{|c|}{ 95.4\% probability } \\
\hline \multirow{2}{*}{ (outside adhesive) } & \multirow{2}{*}{$550 \pm 30$} & \multirow{2}{*}{$600 \pm 30$} & $43.9 \%$ & 1394-1420 Cal & $54.9 \%$ & 1386-1434 Cal \\
\hline & & & $24.3 \%$ & 1326-1344 Cal & $40.5 \%$ & 1311-1359 Cal \\
\hline \multirow{2}{*}{ (outside adhesive) } & \multirow{2}{*}{$540 \pm 30$} & \multirow{2}{*}{$590 \pm 30$} & $54.7 \%$ & 1396-1426 Cal & $65.6 \%$ & 1388-1437 Cal \\
\hline & & & $13.5 \%$ & 1329-1340 Cal & $29.8 \%$ & 1316-1354 Cal \\
\hline \multirow{3}{*}{$\begin{array}{c}\mathrm{C} \\
\text { (inside adhesive) }\end{array}$} & \multirow{3}{*}{$610 \pm 30$} & \multirow{3}{*}{$660 \pm 30$} & $27.5 \%$ & $1302-1328 \mathrm{Cal}$ & $95.4 \%$ & 1295-1404 Cal \\
\hline & & & $27.0 \%$ & 1340-1367 Cal & - & - \\
\hline & & & $13.7 \%$ & 1382-1396 Cal & - & - \\
\hline \multirow{2}{*}{$\begin{array}{c}\mathrm{D} \\
\text { (inside adhesive) }\end{array}$} & \multirow{2}{*}{$650 \pm 30$} & \multirow{2}{*}{$710 \pm 30$} & $37.6 \%$ & 1360-1386 Cal & $51.9 \%$ & 1343-1394 Cal \\
\hline & & & $29.6 \%$ & 1288-1310 Cal & $43.5 \%$ & 1280-1326 Cal \\
\hline
\end{tabular}

\footnotetext{
1) Conventional radiocarbon age: age with $\delta{ }^{13} \mathrm{C}$ correction based on IRMS $\delta{ }^{13} \mathrm{C}(-25.0 \%)$.

2) Measured radiocarbon age: age without $\delta{ }^{13} \mathrm{C}$ correction.
} 
observed as the main component of the matrix whereas $\mathrm{Ca}$ and $\mathrm{P}$ were observed in the particles. Based on the results of chemical component analysis, inorganic materials like $\mathrm{P}_{2} \mathrm{O}_{5}$ and $\mathrm{CaO}$ account for about $60 \%$ of the adhesive, while the LOI accounts for about $40 \%$. Therefore, it was determined that the ratio of inorganic and organic material composition was approximately 60:40. In the XRD analysis, apatite containing $\mathrm{Ca}$ and $\mathrm{P}$ was identified, indicating that the major inorganic component was apatite.

2. Since the IR spectrum was similar to those of bone black, ivory black, and apatite, it was determined that the major inorganic components originated from bones. Furthermore, in the pyrolysis/GC/MS analysis, since Asian lacquer components and oxidized Asian lacquer components were detected in the adhesive, it seems that the adhesive was based on Asian lacquer and oxidation had progressed with the passage of a long period of time.

3. From the radiocarbon dating results, the carbon date of the adhesive(Asian lacquer and bone black) was determined to be between the late $13^{\text {th }}$ century and early $15^{\text {th }}$ century, indicating that it was used in the stone Maitreya during the late Goryeo period.

Based on the above results, it was ascertained that Asian lacquer and bone black were the main components of the adhesive used for installing the glass eyes on the stone standing Maitreya of Daejosa temple, Buyeo. It seems that the bone black was added as a filler for the purpose of improving the workability and viscosity of the adhesive in order to effectively fix the glass eyes.

\section{ACKNOWLEDGMENTS}

This study was supported by the National Research Institute of Cultural Heritage (NRICH) as a part of the Cultural Heritage Research \& Development program; we, hereby, express our gratitude for this. In addition, we express our gratitude to the Conservation Science Division, NRICH for their cooperation in the inorganic analysis.

\section{REFERENCES}

Buyeogun, 1999, Academic investigation and conservation research on the stone standing Maitreya of Daejosa temple. 52. (in Korean)
Cho, N.C., Kim, S.C., Kim, W.H. and Shin, Y.S., 2010, A study on the bonding materials used for the great jar of the Proto-Three Kingdoms period from Daechuri site, Pyeongtaek. Journal of Conservation Science, 26(4), 371376. (in Korean with English abstract)

Choi, S.C., Kim, S.D., Yi, Y.H., Ko, S. and Ham, S.W., 2011, Studies on analysis of Joseon lacquer layer. Journal of Conservation Science, 27(4), 371-380. (in Korean with English abstract)

College of Natural Resources, UC Berkeley, 2019, Granite. https://nature.berkeley.edu/classes/eps2/wisc/granite.html (June 18, 2019)

Gyeong-Dam Conservation Laboratory, 2010, Report on the conservation of lacquer relics excavated at 849-16, Top-dong, Gyeongju city. 130-135. (in Korean)

Institute of Chemistry University of Tartu, Estonia, 2019, Bone black. http://lisa.chem.ut.ee/IR_spectra/paint/pigments/ bone-black/ (June 18, 2019)

Jeong, J.Y. and Myochin, M., 2014, A study of the dried-lacquer amitabha Buddha statue from Simhyangsa temple. Korean Journal of Cultural Heritage Studies, 47(1), 134-151. (in Korean with English abstract)

Jeong, S.K., 2007, A study on the stone Buddha statutes which were made in King of Gwang Jong period of Koryo dynasty. Journal of Korean Cultural History, 27, 579-600. (in Korean with English abstract)

Kang, S.Y., Cho, E.M., Kim, S.H., Kim Y.J. and Lee, J.W., 2014, The application of a chemical assessment of archaeological animal bone by Fourier transform infrared spectroscopy and X-ray diffraction. Analytical Science and Technology, 27(6), 300-307. (in Korean with English abstract)

Kim, S.C., 2007, Analysis and conservation of lacquer wares from archaeological sites in Korea. Ph.D. dissertation, Chungbuk National University, Cheongju, 11-108. (in Korean with English abstract)

Lee, J.W., Kim, S.H., Kim, Y.J., Cho, E.M. and Kang, S., 2014, Conservation status assessment of archaeological bone from Fourier transform infrared spectroscopy and histological analysis. Conservation Studies, 35, 87-98. (in Korean with English abstract)

Lee, S.M., Jeong Y.J., Lee, J.J., Moon, D.H. and Kwon, O.Y., 2018, Material characteristics and provenance presumption of glass used for eyes of the stone standing Maitreya of Daejosa temple, Buyeo(Treasure No. 217). Misulsa Yeongu: Journal of Art History, 35, 67-94. (in Korean with English abstract)

Lu, R., Yoshida, T. and Miyakoshi, T., 2013, Oriental lacquer: A natural polymer. Polymer Reviews, 53(2), 153-191. 
Naju National Research Institute of Cultural Heritage, 2016, Analysis of lacquered specimen from wooden panel and lacqured objects. Excavation report on the Nongso ancient tomb site of Unrim-ri, Sunchang, Naju. 195-211. (in Korean)

Park, J.S. and Lee, J.W., 2017, Analysis of binding media used in mural painting of temple wall by pyrolysis/GC/MS and IR. Journal of Conservation Science, 33(5), 345-354. (in Korean with English abstract)

Ramsey, C.B., 2009, Bayesian analysis of radiocarbon dates. Radiocarbon, 51(1), 337-360.

Reimer, P.J., Bard, E., Bayliss, A., Beck, J.W., Blackwell, P.G., Bronk Ramsey, C., ... van der Plicht, J., 2013, IntCal13 and Marine13 radiocarbon age calibration curves 0-50,000 years Cal BP. Radiocarbon, 55(4), 1869-1887.
Schilling, M.R., Heginbotham, A., van Keulen. H. and Szelewski, M., 2016, Beyond the basics: A systematic approach for comprehensive analysis of organic materials in Asian lacquers. Studies in Conservation, 61(sup3), 3-27.

Wei, S., Pintus, V., Pitthard, V., Schreiner, M. and Song, G., 2011, Analytical characterization of lacquer objects excavated from a Chu tomb in China. Journal of Archaeological Science, 38(10), 2667-2674.

Yang, P.S., 2016, History and concept of binding and restoration. Adhesives for Conservation and Restoration of Cultural Heritage, Daejeon, September 1, 7-18. (in Korean with English abstract)

Yi, Y.H., 1996, Restoration report on the Chosun dynasty lacquered wares inlaid with mother-of-pearl. Journal of Conservation Science, 5(2), 25-34. (in Korean with English abstract) 
